\title{
Contribution of Subsaturating GABA Concentrations to IPSCs in Cultured Hippocampal Neurons
}

\author{
Matthew W. Hill, ${ }^{1}$ P. Amruta Reddy, ${ }^{2}$ Douglas F. Covey, ${ }^{2}$ and Steven M. Rothman ${ }^{1,3}$ \\ ${ }^{1}$ Departments of Neurology and Neurosurgery and ${ }^{2}$ Molecular Biology and Pharmacology, Washington University School \\ of Medicine, St. Louis, Missouri 63110, and 'Department of Pediatric Neurology, St. Louis Children's Hospital, \\ St. Louis, Missouri, 63110
}

The time course of EPSCs and IPSCs is at least partly determined by the concentration profile of neurotransmitter acting on postsynaptic receptors. Several recent reports have suggested that the peak synaptic cleft concentration of the inhibitory neurotransmitter GABA likely reaches at least $500 \mu \mathrm{M}$, a level that saturates the $\mathrm{GABA}_{\mathrm{A}}$ receptor. In the course of investigating the experimental anticonvulsant 3,3-diethyl-2pyrrolidinone (diethyl-lactam), we have observed an important contribution to IPSC decay by subsaturating concentrations of GABA. Diethyl-lactam augments currents elicited by the exogenous application of subsaturating concentrations of GABA in voltage-clamped, cultured hippocampal neurons and significantly prolongs the decay of autaptic IPSCs and miniature IPSCs in our cultures. In addition, diethyl-lactam potentiates currents in excised outside-out membrane patches elicited by the prolonged application of low concentrations of GABA. However, when patches are exposed to 1-2 msec pulses of 1 mM GABA, diethyl-lactam does not alter current decay. Tiagabine, which blocks GABA reuptake, does not prolong IPSCs, so it is unlikely that uptake inhibition accounts for the enhancement of IPSCs. EPSCs and miniature IPSC frequency are unaffected by diethyl-lactam, again consistent with a postsynaptic site of action. We propose that during an IPSC, a substantial number of postsynaptic receptors must be exposed to subsaturating concentrations of GABA. A simplified model of $\mathrm{GABA}_{\mathrm{A}}$ receptor kinetics can account for the effects of diethyllactam on exogenous GABA and IPSCs if diethyl-lactam has its main effect on the monoliganded states of the $\mathrm{GABA}_{\mathrm{A}}$ receptor.

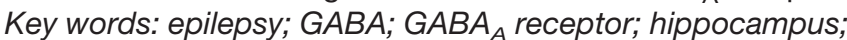
IPSC; outside-out patches; rapid application; synapse
The factors that regulate $\mathrm{GABA}_{\mathrm{A}}$ receptor-mediated inhibitory synaptic transmission are the focus of intense study because GABAergic inhibition plays a significant role in regulating electrical activity in the CNS. Furthermore, the $\mathrm{GABA}_{\mathrm{A}}$ receptor appears to be a target for anticonvulsants, sedative hypnotics, anesthetics, and anxiolytics. Benzodiazepines, barbiturates, neurosteroids, and the $\gamma$-butyrolactones are compounds that are known to enhance GABAergic inhibition (Macdonald et al., 1989b; Twyman and Macdonald, 1992; Rogers et al., 1994; Mathews et al., 1996).

The duration of the synaptic GABA transient is determined by diff usion and uptake, depending on experimental preparation and conditions (Roepstorff and Lambert, 1992, 1994; Isaacson et al., 1993; Draguhn and Heinemann, 1996). The time course of the IPSC is dictated by these factors and by the kinetics of the $\mathrm{GABA}_{\mathrm{A}}$ receptor. Several groups have studied the duration and magnitude of the synaptic GABA transient (Maconochie et al., 1994; Jones and Westbrook, 1995; Tia et al., 1996) and shown that IPSCs can be partly mimicked by exposing excised outside-out patches to high $(\geq 500 \mu \mathrm{M})$ concentrations of GABA for a few milliseconds. These experiments support the idea that IPSCs

Received Jan. 16, 1998; revised April 8, 1998; accepted April 24, 1998.

This work was supported by National Institutes of Health Grant NS14834. We thank Dr. Joe Henry Steinbach for providing suggestions and software for the analysis of miniature IPSCs, Dr. Robert L. Macdonald for valuable criticism, Dr. Kenneth Sommerville (Abbott Laboratories, Chicago, IL) for the gift of tiagabine, and Nancy Lancaster for performing hippocampal dissections and maintaining our cultures.

Correspondence should be addressed to Dr. Steven M. Rothman, Department of Neurology, St. Louis Children's Hospital Room 12E/25, One Children's Place, St. Louis, MO 63110.

Copyright (ㄷ) 1998 Society for Neuroscience $\quad 0270-6474 / 98 / 185103-09 \$ 05.00 / 0$ result from a very brief exposure of postsynaptic receptors to saturating concentrations of GABA.

This experimental technique has also been used to study the mechanisms by which $\mathrm{GABA}_{\mathrm{A}}$ modulators alter IPSCs (Lavoie and Twyman, 1996; Zhu and Vicini, 1997). These nonstationary "concentration jump" experiments may offer more physiological insight than steady-state, single-channel records, because they elucidate effects on receptor states and transitions likely to occur during an IPSC.

The $\gamma$-butyrolactones and their derivatives are $\mathrm{GABA}_{\mathrm{A}}$ modulatory agents of great interest because they demonstrate potent anticonvulsant activity in mice (Klunk et al., 1982a,b; Canney et al., 1991; Holland et al., 1995; Reddy et al., 1996, 1997). We have recently focused our attention on a new analog, 3,3-diethyl-2pyrrolidinone (diethyl-lactam) (Fig. 1), which has a higher therapeutic index than ethosuximide, valproate, and phenobarbital in pentylenetetrazole seizure models (Reddy et al., 1996). It potentiates peak currents elicited by low, but not saturating, GABA concentrations and prolongs IPSC decay. This latter finding interested us because synaptic GABA levels are thought to be saturating.

To characterize diethyl-lactam modulation of IPSC time course, we examined its effect on currents in patches elicited by 1-2 msec applications of $1 \mathrm{~mm}$ GABA. In contrast to its effect on IPSCs, diethyl-lactam did not alter the decay of patch currents. These results suggest that the synaptic GABA concentration transient is subsaturating for a significant proportion of the postsynaptic $\mathrm{GABA}_{\mathrm{A}}$ receptors. These observations support earlier conclusions based on the modulation of IPSCs and miniature IPSCs by benzodiazepines (Rogers et al., 1994; Frerking et al., 
<smiles>[R]C1([R])CCOC1=O</smiles>

$\alpha$-Substituted $\gamma$-butyrolactone

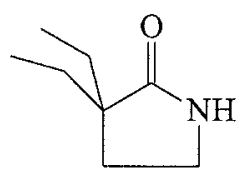

\section{3,3-Diethyl-2-pyrrolidinone (diethyl-lactam)}

Figure 1. Chemical structures of $\alpha$-substituted $\gamma$-butyrolactone and diethyl-lactam.

1995; Perrais and Ropert, 1997) and on the rapid application of subsaturating GABA concentrations (Galarreta and Hestrin, 1997). Moreover, they indicate that rapid application of saturating GABA concentrations, although very useful in the study of $\mathrm{GABA}_{\mathrm{A}}$ receptor kinetics, fails to duplicate important features of the synaptic GABA transient.

\section{MATERIALS AND METHODS}

Materials. Diethyl-lactam was prepared according to the method reported for the synthesis of 3,3-dialkyl-2-pyrrolidinones (Reddy et al., 1996). Drug stock solutions were made in DMSO and diluted with extracellular recording solution to their final concentrations. Control and drug solutions contained the same concentration of DMSO. We purchased $N-(2,6-$ dimethylphenylcarbamoylmethyl)triethylammonium bromide (QX314) and 1,2,3,4-tetrahydro-6-nitro-2,3-dioxo-benzo[f]quinoxaline-7sulfonamide (NBQX) from Research Biochemicals (Natick, MA). Tiagabine was a gift from Dr. Kenneth Sommerville (Abbott Laboratories, Chicago, IL). All other chemicals were purchased from Sigma (St. Louis, MO) unless otherwise mentioned.

Cell culture. Hippocampi were dissected from 1-d-old Sprague Dawley rat pups, cut into pieces $(<1 \mathrm{~mm})$, and placed in $3 \mathrm{ml}$ of Leibovitz's L-15 medium containing $1 \mathrm{mg} / \mathrm{ml}$ papain and $0.2 \mathrm{mg} / \mathrm{ml}$ bovine serum albumin. The hippocampi were triturated with Pasteur pipettes, and the suspension was centrifuged through $2 \mathrm{ml}$ of medium containing $10 \mathrm{mg} / \mathrm{ml}$ trypsin inhibitor and $10 \mathrm{mg} / \mathrm{ml}$ bovine serum albumin. The cells were then resuspended in growth medium containing 90\% Eagle's minimal essential medium (without glutamine), 10\% NuSerum (Collaborative Research), $20 \mathrm{U} / \mathrm{ml}$ penicillin, and $20 \mu \mathrm{g} / \mathrm{ml}$ streptomycin. They $(2.5 \times$ $10^{5}$ cells per dish) were then plated onto a monolayer of cortical glial cells in $35 \mathrm{~mm}$ culture dishes that had been precoated with poly-L-lysine. For the study of synaptic currents, neurons were plated onto dishes containing isolated glial "microislands" formed by preplating the glia into dishes that had been sprayed with collagen droplets using a microatomizer (Thomas Scientific, Swedesboro, NJ) according to previously published methods (Mennerick et al., 1995).

Electrophysiology. Experiments were performed at room temperature $\left(\sim 25^{\circ} \mathrm{C}\right)$ on the stage of an inverted microscope (Nikon) using whole-cell patch-clamp techniques. Growth medium was replaced with an extracellular recording solution containing (in $\mathrm{mm}$ ): $140 \mathrm{NaCl}, 3 \mathrm{KCl}, 10$ HEPES, and 5.5 glucose, $\mathrm{pH} 7.3$, with $\mathrm{NaOH}$. For studies of exogenously applied GABA currents, $5 \mathrm{~mm} \mathrm{MgCl}_{2}$ was included. Synaptic studies used $5 \mathrm{mM} \mathrm{CaCl}_{2}$ and $5 \mathrm{mM} \mathrm{MgCl}_{2}$. For excised patch experiments, $2 \mathrm{~mm}$ $\mathrm{CaCl}_{2}$ and $1 \mathrm{mM} \mathrm{MgCl}$ were used. When miniature IPSCs were recorded, $2 \mathrm{mM} \mathrm{CaCl}_{2}, 1 \mathrm{~mm} \mathrm{MgCl}_{2}, 1 \mu \mathrm{M}$ TTX, $100 \mu \mathrm{M} \mathrm{APV}$, and $10 \mu \mathrm{M}$ NBQX were added to the extracellular solution. For experiments examining currents induced by exogenous GABA, the pipette solution contained (in mM): $130 \mathrm{CsCl}, 10$ TEA Cl, 10 HEPES, 1.1 EGTA, 2 QX314, 5.5 glucose, and $2 \mathrm{Mg} \mathrm{ATP}, \mathrm{pH} \mathrm{7.2,} \mathrm{with} \mathrm{CsOH}$. For excised patch experiments, the internal solution contained (in mM): $130 \mathrm{CsCl}, 10$ TEA $\mathrm{Cl}, 10$ HEPES, 10 EGTA, 5.5 glucose, and $2 \mathrm{Mg}$ ATP, pH 7.2. For synaptic current experiments, the internal solution contained: $140 \mathrm{KCl}$, 10 HEPES, 1.1 EGTA, 5.5 glucose, and $2 \mathrm{Mg}$ ATP, pH 7.2, with KOH.

In the whole-cell experiments, solutions were applied via gravity-fed microperfusion pipettes $(\sim 300 \mu \mathrm{m}$ in diameter $)$ positioned $\sim 200 \mu \mathrm{m}$ from the cell under study. Flow was gated by computer-controlled sole- noid valves (The Lee Company, Westbrook, CT). Recordings were performed using an Axopatch-1B amplifier (Axon Instruments, Foster City, CA). Pipette and whole-cell capacitance as well as series resistance were corrected by the compensation circuitry on the amplifier. Final series resistance values were typically $8-10 \mathrm{M} \Omega$, and compensation of $\geq 80 \%$ was possible without significant oscillation.

When we examined GABA-induced currents, neurons were clamped at $-60 \mathrm{mV}$ and exposed to $400 \mathrm{msec}$ pulses of GABA with and without drug solutions. The resulting currents were filtered at $1 \mathrm{kHz}$ and digitized at $1 \mathrm{kHz}$ using an analog-to-digital converter and a $\mathrm{PC}$ running commercial software (pClamp6, Axon Instruments). During synaptic studies, neurons isolated on glial microislands were voltage clamped at $-60 \mathrm{mV}$ and then depolarized to $+20 \mathrm{mV}$ for $2 \mathrm{msec}$. The resulting postsynaptic currents were identified as either excitatory or inhibitory by their time course and their sensitivity to $100 \mu \mathrm{M}$ bicuculline.

For the rapid application of GABA, solutions were applied from a double-barrel glass "theta tube" mounted on a piezoelectric translator (Burleigh, Fishers, NY). The two barrels of the theta tubing contained continuously flowing extracellular solution (ECS) and GABA solution, respectively. To examine the effect of different drugs on patch currents, the drugs were added to both the ECS and GABA solutions. Outside-out patches were excised from neurons and positioned adjacent to the interface of the solutions flowing through the theta tubing. The digital-toanalog output from our computer interface was used to trigger a $70 \mu \mathrm{m}$ displacement and return of the piezoelectric translator, moving the solution interface over the patch. We estimated the speed of solution exchange by recording the open tip potentials with solutions of different ionic strength after expelling the patch from the electrode. We achieved $10-90 \%$ solution exchange times that were typically $<500 \mu \mathrm{sec}$, and exposure times ranged from 1.6 to $2.5 \mathrm{msec}$. These currents were digitized at $10 \mathrm{kHz}$. The patches for rapid $1 \mathrm{~mm}$ GABA application experiments as well as those for prolonged $3 \mu \mathrm{M}$ GABA applications were voltage-clamped at a slightly depolarized potential $(-30 \mathrm{mV})$ to improve their stability.

Data analysis. For experiments involving exogenous application of GABA, we measured peak currents. Patch currents and IPSCs (when applicable) were fit to second-order exponential equations and analyzed for half decay time $\left(t_{1 / 2}\right)$ and charge transfer using commercial software (pClamp6). EPSCs were fit to first-order exponential equations. Frequency, amplitudes, and decays of miniature IPSCs were analyzed with software kindly provided by Dr. Joe Henry Steinbach (Department of Anesthesiology, Washington University School of Medicine). Measured parameters are reported as the mean $\pm \mathrm{SE}$.

The normalized GABA concentration-response curve and the diethyllactam concentration-response curve were both fit (Origin, Microcal, Northampton, MA) to the logistic equation: $Y=\left(A_{1}-A_{2}\right) /(1+$ $\left.\left([\text { agonist }] / \mathrm{EC}_{50}\right)^{\mathrm{p}}\right)+A_{2}$, where $A_{1}$ represents the initial (minimum) $Y$ value, $A_{2}$ is the final (maximum) $Y$ value, $p$ is the power (or Hill coefficient), and the $Y$ value at [agonist] $=\mathrm{EC}_{50}$ is halfway between the two limiting values. We simulated diethyl-lactam's modulation of the $\mathrm{GABA}_{\mathrm{A}}$ receptor with commercial software (Scientist; Micromath, Salt Lake City, UT).

\section{RESULTS}

\section{Diethyl-lactam potentiates GABA currents and autaptic IPSCs}

Diethyl-lactam has demonstrated potent anticonvulsant activity in mouse seizure models and was shown to potentiate $\mathrm{GABA}_{\mathrm{A}}$ receptor-mediated currents (Reddy et al., 1996). In this study, cultured rat hippocampal neurons were voltage clamped at -60 $\mathrm{mV}$ and exposed to $400 \mathrm{msec}$ applications of $3 \mu \mathrm{M}$ GABA in the presence and absence of drug. When coapplied with GABA, diethyl-lactam potentiated peak inward currents in a concentration-dependent manner (Fig. $2 A, B$ ). We also examined the effect of diethyl-lactam on the GABA concentrationresponse curve. Like other $\gamma$-butyrolactone-class drugs, it augmented peak currents elicited by low, but not saturating, concentrations of GABA (Fig. 2C).

We next determined whether diethyl-lactam was able to potentiate the GABAergic IPSCs in our cultures. To observe synaptic effects, autaptic IPSCs were recorded from neurons isolated 
A.
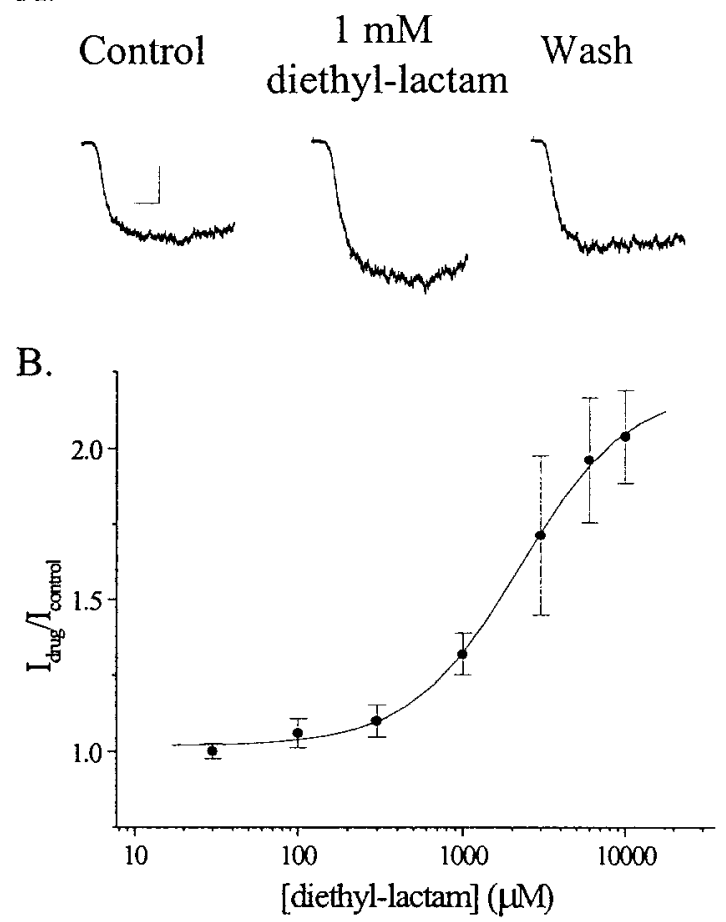

C.
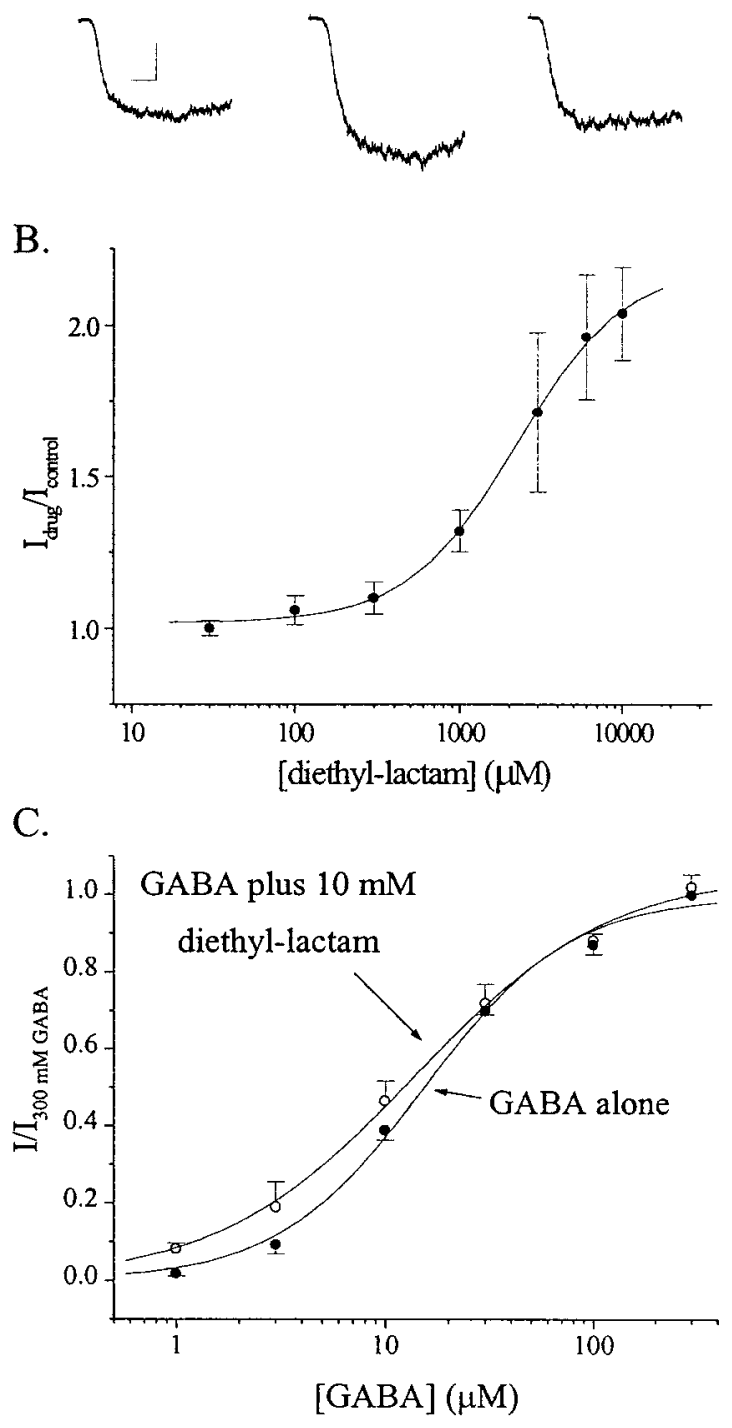

Figure 2. Diethyl-lactam modulation of whole-cell $\mathrm{GABA}_{\mathrm{A}}$ currents. $A$, Hippocampal neurons were voltage clamped at $-60 \mathrm{mV}$ and exposed to exogenous application of $3 \mu \mathrm{M}$ GABA $\pm 1 \mathrm{~mm}$ diethyl-lactam. Sample currents are shown. Calibration: $200 \mathrm{pA}, 500 \mathrm{msec}$. B, Diethyl-lactam exhibited a concentration-dependent potentiation of peak currents with an apparent $\mathrm{EC}_{50}$ of $2.2 \mathrm{mM}$. Each point represents the mean $\pm \mathrm{SE}$ of at least five cells. $C$, Diethyl-lactam altered the GABA concentrationresponse curve by augmenting currents elicited by low but not saturating concentrations of GABA. Each point represents the mean \pm SE of at least five cells. All currents are normalized to those elicited by $300 \mu \mathrm{M}$ GABA without drug. For GABA alone, $\mathrm{EC}_{50}$ and Hill coefficient were 15.3 and $1.2 \mu \mathrm{M}$, respectively. In the presence of $10 \mathrm{~mm}$ diethyl-lactam, the $\mathrm{EC}_{50}$ was $13.8 \mu \mathrm{M}$ and the Hill coefficient was $0.9 \mu \mathrm{M}$.

on individual glial microislands. Diethyl-lactam exhibited a concentration-dependent, reversible prolongation in the duration of IPSC decay (Fig. $3 A$ ). In 14 cells, the $t_{1 / 2}$ and charge transfer of IPSC decays were measured in control and drug solutions (Table 1). The effects of the drug on both these parameters were statistically significant. Nine of the IPSCs were well fit by the sum of two exponential decays (Table 1). Diethyl-lactam elicited a
A.

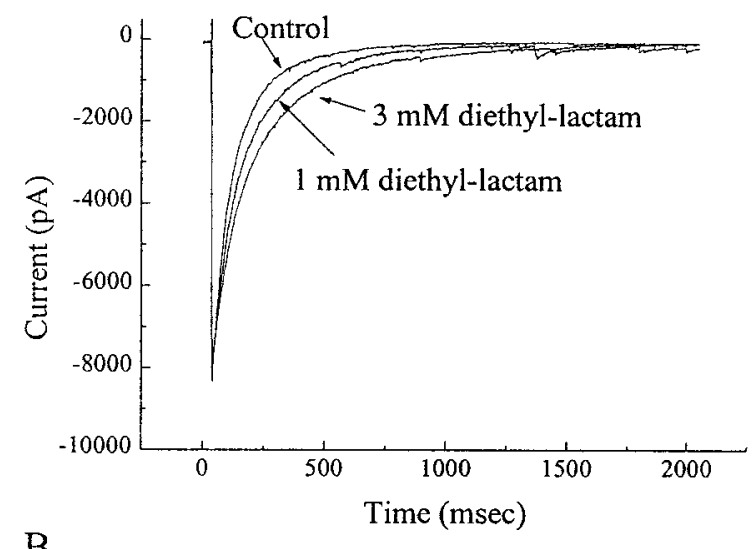

B.

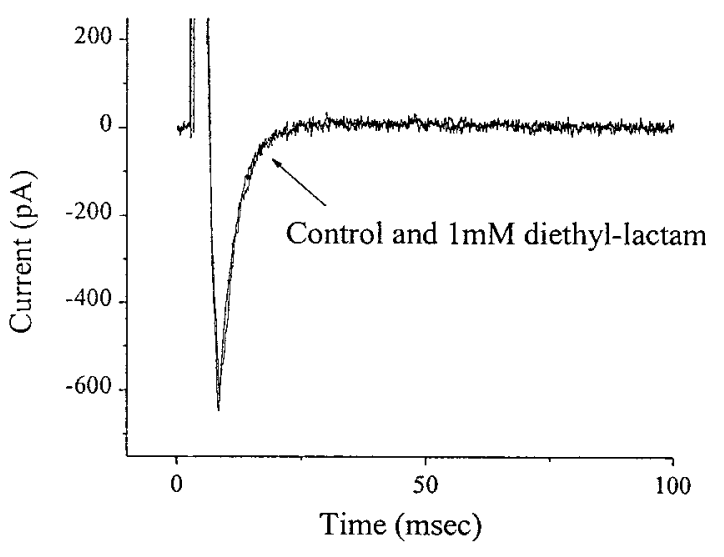

C.

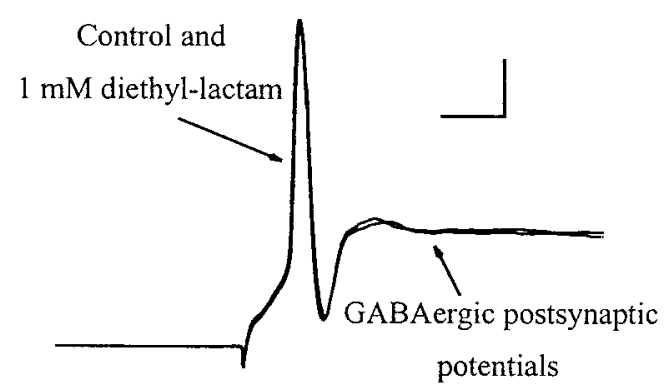

Figure 3. Diethyl-lactam effects on synaptic transmission. A, Sample IPSC in the presence of control, 1 and $3 \mathrm{~mm}$ diethyl-lactam solutions. $B$, Sample EPSC in control and $1 \mathrm{~mm}$ diethyl-lactam solutions. $C$, Currentclamped microisland neurons adjusted to potentials of $-60 \mathrm{mV}$, and then stimulated with $5 \mathrm{msec}$ depolarizing current steps exhibited action potentials and resulting autaptic postsynaptic potentials. Action potentials were not altered by diethyl-lactam. Calibration: $5 \mathrm{msec}, 20 \mathrm{mV}$.

statistically significant prolongation in both the fast and slow time constants, but not their relative contributions to current decay.

Although we found that diethyl-lactam clearly prolonged IPSCs in our preparation, there was no evidence for any effect on peak amplitude or time course of glutamatergic EPSCs (Fig. 3B). In six cells, peak amplitudes in $1 \mathrm{~mm}$ diethyl-lactam solutions were $96.3 \pm 4.6 \%$ of control, and $\tau$ values were $96.4 \pm 3.5 \%$ of control ( $p>0.05$ for both, paired $t$ test). This implies that diethyl-lactam affects IPSCs by modulating the postsynaptic $\mathrm{GABA}_{\mathrm{A}}$ receptor because presynaptic effects, such as an alteration of voltage-gated 


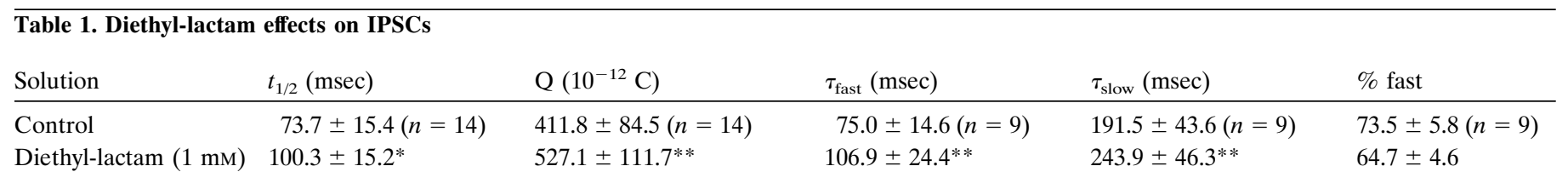

${ }^{*} p<0.05$, paired $t$ test.

${ }^{* *} p<0.01$, paired $t$ test.

channels governing transmitter release, might be expected to alter EPSCs. In support of this hypothesis, action potentials recorded in current-clamp configuration were unaltered by the presence of diethyl-lactam (Fig. 3C).

To further test the hypothesis of a postsynaptic effect of diethyl-lactam, we analyzed miniature IPSCs (mIPSCs) from five neurons and determined their frequency, amplitude, and $t_{1 / 2}$ of current decay (Fig. 4A). The cumulative probability plots for $t_{1 / 2}$ demonstrated that diethyl-lactam $(1 \mathrm{~mm})$ caused a statistically significant prolongation of mIPSC decay in five of five cells observed (Fig. $4 B$ ) but no consistent effect on amplitude. Furthermore, in the presence of drug, mIPSC frequency was not significantly different from control solution values $(95.7 \pm 5.4 \%$ of control; $n=5 ; p>0.05$, paired $t$ test). The lack of an effect on mIPSC frequency is additional evidence against a presynaptic site of action for diethyl-lactam.

As an additional control for a presynaptic effect of diethyllactam, we determined whether inhibition of GABA reuptake could account for diethyl-lactam's prolongation of IPSCs. We recorded autaptic IPSCs in the presence of $50 \mu \mathrm{M}$ tiagabine, an inhibitor of electrogenic GABA transporters (Braestrup et al., 1990). This treatment produced no significant effect on any parameter derived from second-order exponential decay equation fits $\left(n=14 ; p>0.05\right.$ for $\tau_{\text {fast }}, \tau_{\text {slow }}$, and percent fast, paired $t$ test). This result suggests that in our microisland culture system, GABA uptake was not a significant factor in determining IPSC time course, making it unlikely that diethyl-lactam prolongs IPSCs by inhibiting these transporters.

\section{Diethyl-lactam effects on patch currents}

We used a "rapid application" technique with excised, outside-out patches to investigate the postsynaptic effects of diethyl-lactam in more detail. Although peak currents elicited by slow application of saturating GABA concentrations were not altered by diethyllactam, it was still possible that deactivation observed after extremely brief application of high GABA concentrations might be prolonged by diethyl-lactam. This brief duration of GABA application more closely resembles synaptic transmission. Using a piezoelectric translator and theta tubing, we were able to achieve solution exchange in $<1 \mathrm{msec}$, exposing $\mathrm{GABA}_{\mathrm{A}}$ receptors in excised patches to test solutions for extremely brief periods. This allowed us to simulate IPSCs and accurately measure current deactivation rates.

We found that diethyl-lactam $(1 \mathrm{~mm})$ did not affect any parameter of the decay of currents elicited by brief applications of $1 \mathrm{~mm}$ GABA (Table $2 A$, Fig. 5A). Although GABA was applied for 1-2 msec, diethyl-lactam was preapplied through the ECS side of the theta tubing (as well as coapplied with GABA) to ensure that it had sufficient time to bind to patch receptors. When similar experiments were performed with GABA and $300 \mu \mathrm{M}$ phenobarbital, there was a significant prolongation of current decay (Table $2 B$; Fig. $5 B$ ). Because it is known that barbiturates increase the mean open duration of $\mathrm{GABA}_{\mathrm{A}}$ receptors (Macdonald et al.,
A.

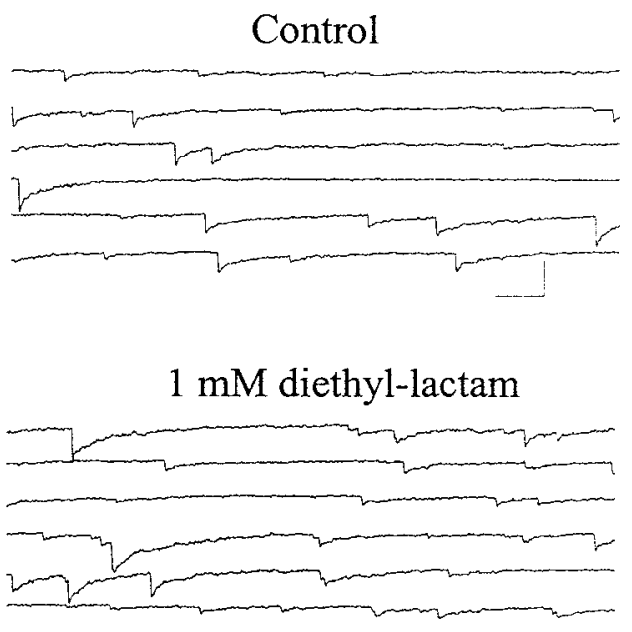

B.

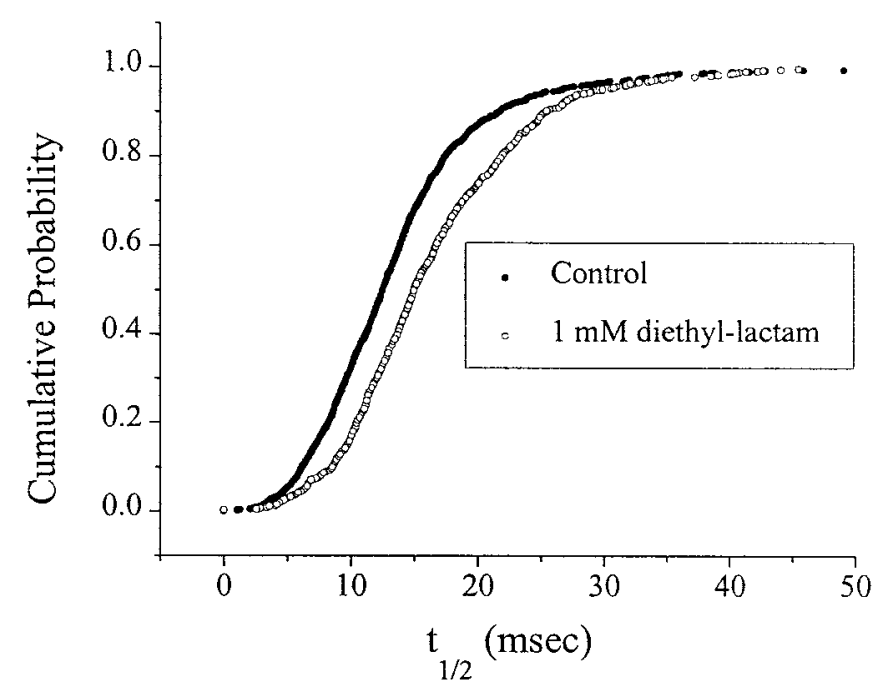

Figure 4. Diethyl-lactam modulation of mIPSC duration. $A$, Spontaneous currents were recorded in five cells using solutions containing TTX, NBQX, and APV. Shown are sample mIPSCs recorded under control conditions (top) and in the presence of $1 \mathrm{~mm}$ diethyl-lactam (bottom). Calibration bar, $50 \mathrm{msec}$ and $200 \mathrm{pA}$. B, The half-decay time $\left(t_{1 / 2}\right)$ for each detectable independent miniature event was acquired and displayed in a cumulative probability plot. A representative plot from one cell is displayed, showing 1290 miniature events recorded under control conditions and 683 recorded in the presence of $1 \mathrm{~mm}$ diethyl-lactam. In every cell studied, $1 \mathrm{~mm}$ diethyl-lactam elicited a statistically significant increase in half-decay time $(p<0.05$; Kolmogorov-Smirnov test). The currents displayed in $A$ and summarized in $B$ were recorded from different cells. 


\begin{tabular}{|c|c|c|c|c|}
\hline$\underline{\text { Solution }}$ & $t_{1 / 2}(\mathrm{msec})$ & $\tau_{\text {fast }}(\mathrm{msec})$ & $\tau_{\text {slow }}(\mathrm{msec})$ & $\%$ fast \\
\hline \multicolumn{5}{|l|}{ Diethyl-lactam } \\
\hline Control $(n=15)$ & $53.3 \pm 6.8$ & $31.5 \pm 2.8$ & $196.6 \pm 14.1$ & $51.1 \pm 3.4$ \\
\hline Diethyl-lactam (1 mм) & $52.9 \pm 6.4$ & $34.0 \pm 4.8$ & $197.3 \pm 21.4$ & $50.4 \pm 2.9$ \\
\hline \multicolumn{5}{|l|}{ Phenobarbital } \\
\hline Control $(n=11)$ & $29.7 \pm 3.5$ & $24.1 \pm 3.3$ & $117.7 \pm 12.9$ & $53.8 \pm 2.6$ \\
\hline Phenobarbital $(300 \mu \mathrm{M})$ & $64.7 \pm 8.3^{*}$ & $25.4 \pm 5.2$ & $175.7 \pm 16.7^{* *}$ & $35.1 \pm 4.2^{* *}$ \\
\hline
\end{tabular}

$* p<0.05$, paired $t$ test.

**p $p<0.01$, paired $t$ test.

1989b), one might expect such an effect. This observation verified that we could observe prolongation of current decay with at least one established $\mathrm{GABA}_{\mathrm{A}}$ receptor modulator. This concern is not trivial, because others have reported that patch excision alters kinetic properties of the $\mathrm{GABA}_{\mathrm{A}}$ receptor and response to various modulators (Frosch et al., 1992; Banks et al., 1997). Although the patches sampled for the phenobarbital experiments decayed more rapidly than those studied in the diethyl-lactam experiments (compare control $t_{1 / 2}$ values in Table 2, we still failed to see an effect of diethyl-lactam when we confined our analysis to those patches that had a $t_{1 / 2}$ value of $<50 \mathrm{msec}$ (control, $29.1 \pm 4.7 \mathrm{msec}$; drug, $30.0 \pm 3.9 \mathrm{msec} ; n=7$; Fig. $5 C$ ).

Finally, we verified that the $\mathrm{GABA}_{\mathrm{A}}$ receptors in our excised patches were still sensitive to modulation by diethyl-lactam by exposing them to prolonged $(400 \mathrm{msec})$ applications of $3 \mu \mathrm{M}$ GABA \pm drug (Fig. 6). In 10 patches, $1 \mathrm{~mm}$ diethyl-lactam increased peak currents to $130 \pm 8 \%$ of control $(p<0.05$, paired $t$ test). In seven more patches, $10 \mathrm{~mm}$ diethyl-lactam nearly doubled peak currents ( $194 \pm 18 \%$ of control; $p<0.01$, paired $t$ test). In comparison, whole-cell currents were potentiated to $132 \pm 7 \%$ and $204 \pm 15 \%$ of control by 1 and $10 \mathrm{~mm}$ diethyl-lactam, respectively (Fig. 2). We can therefore conclude that patch excision does not render the receptors insensitive to diethyl-lactam.

\section{The effect of diethyl-lactam on simulated patch currents and IPSCs}

We were initially bothered by the absence of any diethyl-lactam effect on the deactivation of currents induced by high concentrations of GABA in outside-out patches. We had suspected that it would slow deactivation, thus explaining IPSC effects by a modulation of postsynaptic $\mathrm{GABA}_{\mathrm{A}}$ receptors. However, the seemingly discordant observations of diethyl-lactam's effects on IPSCs and patch currents can be reconciled. We realized that the patch experiments do not replicate the actual synaptic GABA concentration transient. Although the peak GABA concentration in the cleft may be saturating, receptors more distant from the vesiclerelease site may be exposed to subsaturating levels of GABA during an IPSC (Mody et al., 1994; Perrais and Ropert, 1997). Alternatively, physiological transmitter clearance mechanisms may allow persistence of low levels of GABA close to release sites after the initial "burst" of saturating transmitter levels.

Using a previously described model of $\mathrm{GABA}_{\mathrm{A}}$ receptor kinetics (Jones and Westbrook, 1995), we found that we could simulate the salient features of all our experimental observations (Fig. 7). For the diethyl-lactam simulations, we assumed that the probability of entering the monoliganded open state must be increased because diethyl-lactam alters the GABA concentration-response relation only at low GABA concentrations (see Discussion). We therefore only changed the opening rate constant $\left(O_{1}\right)$ for the monoliganded open state $\left(\mathrm{GR}^{\circ}\right)$ from 200 to $610 \mathrm{sec}^{-1}$ (Fig. $7 A$ ).
The simulated GABA concentration-response curves calculated at intervals between 1 and $300 \mu \mathrm{M}$ GABA in the presence and absence of diethyl-lactam approximated our experimental data (compare Figs. $7 B, 2 C$ ). These curves were constructed by simulating the GABA exposure with a 400 msec step and recording the peak open probability. These values were then normalized to the open probability at $300 \mu \mathrm{M}$ GABA. The simulated control GABA $\mathrm{EC}_{50}$ is 18.4 and the Hill coefficient is $1.1 \mu \mathrm{M}$; in the presence of diethyl-lactam, the $\mathrm{EC}_{50}$ and Hill coefficient decrease to 11.0 and $1.0 \mu \mathrm{M}$, respectively. In comparison, our experimental data revealed an $\mathrm{EC}_{50}$ of 15.3 and a Hill coefficient of $1.2 \mu \mathrm{M}$ under control conditions. In the presence of diethyl-lactam (10 $\mathrm{mm})$, the $\mathrm{EC}_{50}$ and Hill coefficient values were 13.8 and $0.9 \mu \mathrm{M}$, respectively.

To simulate the patch currents, we drove the model with a 1 msec GABA concentration step to $1 \mathrm{~mm}$. As expected, using the model and rate constants of Jones and Westbrook (1995), the simulated control currents were in good agreement with our experimental observations. In order for the model IPSC to qualitatively resemble our experimental data, we required a transient with an instantaneous rise followed by a decay, described by the sum of two exponentials (amplitudes, 750 and $10 \mu \mathrm{M}$; time constants, $800 \mu \mathrm{sec}$ and $133 \mathrm{msec}$, respectively). The initial GABA concentration is in the saturating range for the $\mathrm{GABA}_{\mathrm{A}}$ receptor, but it is smaller than the peak of the biexponential glutamate transient suggested by Clements (1996) for EPSCs in cultured hippocampal neurons (amplitudes, $2.7 \mathrm{~mm}$ and $400 \mu \mathrm{M}$ ). Furthermore, our two decay time constants are longer than the proposed EPSC values (100 $\mu \mathrm{sec}$ and $2.1 \mathrm{msec})$. When $O_{1}$ was changed from 200 (control) to $610 \mathrm{sec}^{-1}$ (diethyl-lactam) and our proposed GABA transient was used to drive the IPSC simulation, the current decay was prolonged, but the simulated patch current (driven by a $1 \mathrm{msec}$ pulse of $1 \mathrm{~mm}$ GABA) was unaffected (Fig. $7 C, D)$.

\section{DISCUSSION}

These experiments, which have better characterized the action of diethyl-lactam, have also refined our understanding of selected aspects of inhibitory synaptic transmission. We found that diethyllactam prolonged IPSCs and augmented GABA-induced currents in cultured hippocampal neurons. We were initially concerned that our results were internally contradictory; although diethyl-lactam prolonged the decay of IPSCs, which is likely mediated by high $(>500 \mu \mathrm{M})$ peak synaptic cleft GABA concentrations, it had no effect on steady-state whole-cell currents produced by application of $>100 \mu \mathrm{M}$ GABA.

We considered the possibility that diethyl-lactam potentiated IPSCs through a presynaptic mechanism but found no evidence to support this hypothesis. Although it prolonged miniature IPSC 
A.

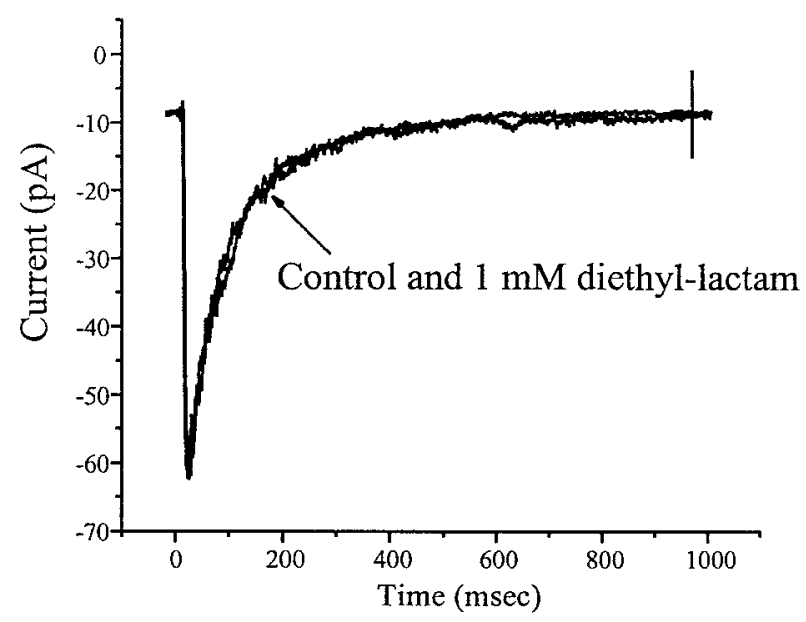

B.

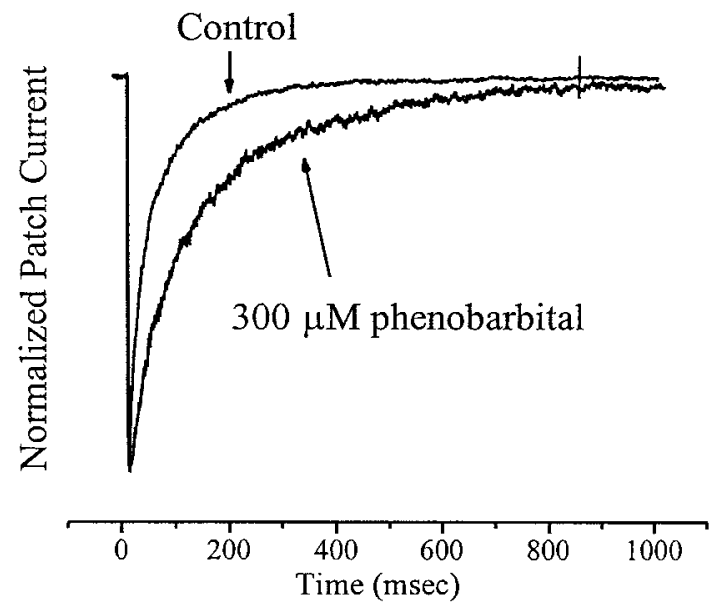

C.

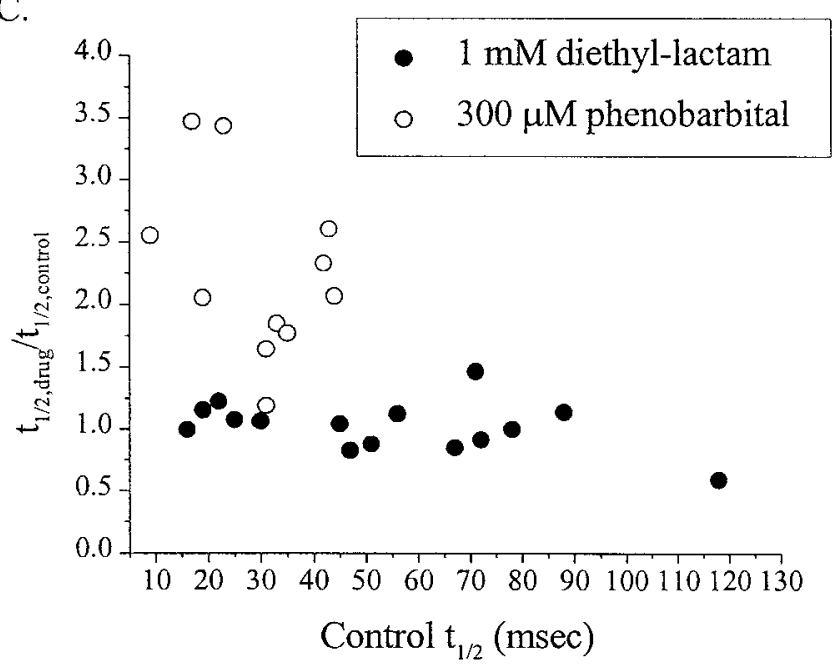

Figure 5. Rapid application of saturating GABA to excised patches. $A$, Sample currents in an excised patch elicited by brief $(1.6 \mathrm{msec})$ applications of $1 \mathrm{~mm}$ GABA $\pm 1 \mathrm{~mm}$ diethyl-lactam. In the GABA + diethyl-lactam exposures, diethyl-lactam was present in the ECF barrel of the theta tubing, so the patches were exposed to the compound before the brief application of GABA + diethyl-lactam. The drug had no effect on the current decay. B, Patch-current decay was prolonged by $300 \mu \mathrm{M}$ phenobarbital. $C$, Ratio of $t^{1 / 2, \text { drug }}$ to $t^{1 / 2, \text { control }}$ plotted versus $t^{1 / 2,{ }^{2} \text {, control }}$. Diethyllactam did not prolong $t_{1 / 2}$ even in those patches that had fast control $t_{1 / 2}$ values, therefore the phenobarbital effect cannot be explained by selection for patches with rapid current decay.
Control

A.

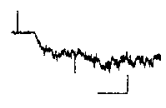

B.

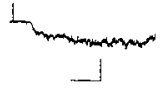

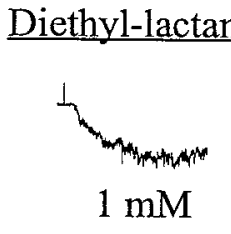

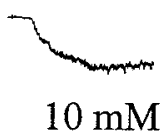

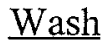
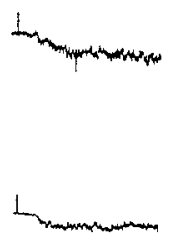

Figure 6. Diethyl-lactam effects on subsaturating GABA currents in patches. $A$, Sample current from an excised patch elicited by the prolonged application of $3 \mu \mathrm{M}$ GABA $\pm 1 \mathrm{~mm}$ diethyl-lactam. Calibration: 20 pA, 200 msec. $B$, Sample current from another excised patch elicited by the prolonged application of $3 \mu \mathrm{M}$ GABA $\pm 10 \mathrm{~mm}$ diethyl-lactam. Calibration: $50 \mathrm{pA}, 200 \mathrm{msec}$. Patch excision does not render $\mathrm{GABA}_{\mathrm{A}}$ receptors insensitive to modulation.

decay, it had no effect on their frequency. Furthermore, it had no effect on EPSCs, which might be expected if it acted presynaptically (or postsynaptically to alter passive electrical properties of the dendrites). It did not alter the amplitude or duration of action potentials. Finally, blockade of GABA reuptake cannot account for diethyl-lactam's prolongation of IPSCs, because a known reuptake inhibitor (tiagabine) failed to alter our IPSCs.

The lack of diethyl-lactam's effect on peak currents induced by several-hundred-millisecond applications of $>100 \mu \mathrm{M}$ GABA led us to consider that the compound might alter the kinetics of $\mathrm{GABA}_{\mathrm{A}}$ receptor deactivation. Such an effect might only be apparent with rapid GABA application. However, diethyl-lactam failed to prolong the decays of currents elicited by a 1-2 msec application of GABA (1 mM) to excised patches. It is unlikely that patch excision altered the sensitivities of the receptors to pharmacological modulators, because phenobarbital was still able to slow current deactivation with rapid GABA applications, and currents elicited by long exposures of $3 \mu \mathrm{m}$ GABA were still potentiated by diethyl-lactam. However, it is conceivable that the $\mathrm{GABA}_{\mathrm{A}}$ receptor subunits that form the postsynaptic receptors have different pharmacological properties than the subunits present in our excised patches. This represents a limitation of this experimental technique.

The most economical explanation for the augmentation of IPSCs and mIPSCs is that diethyl-lactam potentiates currents induced by subsaturating concentrations of GABA, which must be present at some point during the course of the synaptic current. We suspect that the solution exchange is so rapid when we apply GABA (1 mM) to excised patches that we never observe subsaturating GABA currents and, therefore, see no diethyllactam effects. A corollary point is that rapid application of neurotransmitter to patches does not reliably duplicate synaptic conditions. This is attributable to the inability of this type of application system to faithfully reproduce the true synaptic transmitter concentration transient. During a patch current, receptors are uniformly exposed to saturating concentrations of transmitter, whereas during a synaptic event, a significant portion of postsynaptic receptors may "see" lower concentrations of GABA as a result of diffusion or "spillover" of transmitter (Isaacson et al., 1993; Roepstorff and Lambert, 1994). In addition, physiological transmitter clearance mechanisms (diff usion and uptake) may not be as rapid as the submillisecond washout caused by the movement of a piezoelectric device. 

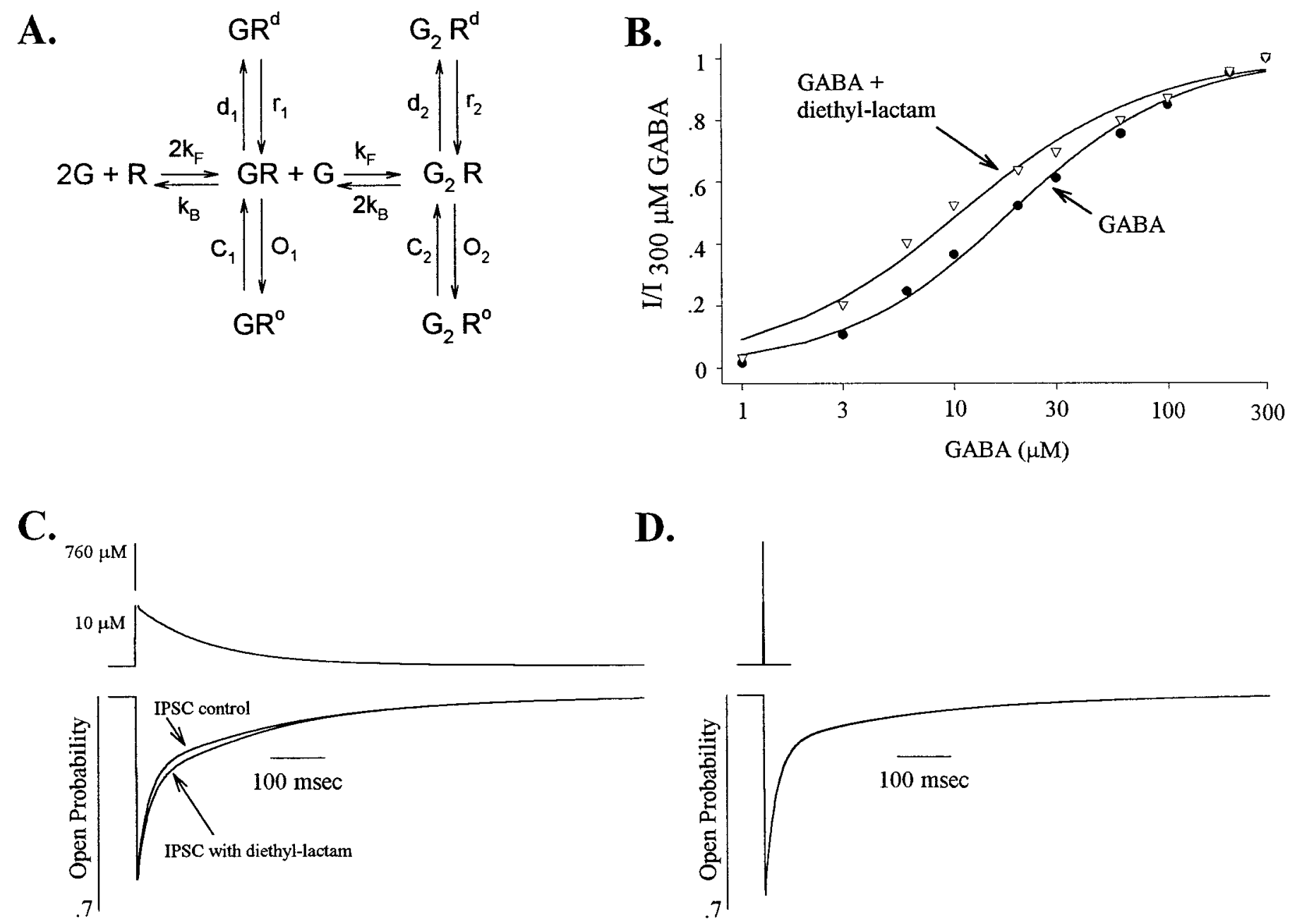

Figure 7. Simulation of diethyl-lactam effects on $\mathrm{GABA}_{\mathrm{A}}$ receptors. $A$, Previously published kinetic scheme for $\mathrm{GABA}_{\mathrm{A}}$ receptor activation, deactivation, and desensitization (Jones and Westbrook, 1995). Values for the control rate constants are as follows: $k_{\mathrm{F}}, 3 \mu \mathrm{M}^{-1} ; k_{\mathrm{B}}, 150 ; d_{1}, 13 ; r_{1}, 0.13$; $d_{2}, 750 ; r_{2}, 15 ; C_{1}, 1111 ; O_{1}, 200 ; C_{2}, 142 ;$ and $O_{2}, 2500$, all sec ${ }^{-1}$. In our model, diethyl-lactam increases $O_{1}$ from 200 to 610 sec ${ }^{-1}$. $B$, Concentration-response curves calculated for GABA and GABA + diethyl-lactam. The peak currents induced by a simulated step of GABA (400 $\mathrm{msec}$ ) were calculated at concentrations between 1 and $300 \mu \mathrm{M}$ GABA. The points were then fit by a logistic equation to give the two continuous lines. The control $\mathrm{EC}_{50}$ is 18.4, and the Hill coefficient is $1.1 \mu \mathrm{M}$; diethyl-lactam reduces the $\mathrm{EC}_{50}$ to 11.0 and the Hill coefficient to $1.0 \mu \mathrm{M}$ (compare with Fig. $2 C$ ). $C$, IPSC simulated by a GABA transient that decays as the sum of two exponentials (top trace, amplitudes 750 and $10 \mu \mathrm{M}$; time constants, $800 \mu$ sec and $133 \mathrm{msec}$, respectively). The gap in the display of the GABA transient (top trace) is necessary because the difference in the amplitudes of the two summed components is so large. The simulated addition of diethyl-lactam prolongs the decay of the IPSC. $D$, Patch currents simulated by a step application of GABA ( $1 \mathrm{~mm}$ for $1 \mathrm{msec}$, top trace). The presence of diethyl-lactam had virtually no effect on current deactivation because the two separate current traces in the figure completely superimpose.

There are some similarities between our findings with diethyllactam and observations with benzodiazepines, which augment IPSCs in other preparations. Benzodiazepines also potentiate currents induced by subsaturating concentrations of GABA. Based on electrophysiological measurements, they increase the affinity of the $\mathrm{GABA}_{\mathrm{A}}$ receptor for GABA without altering maximum current (Choi et al., 1981; Rogers et al., 1994; Lavoie and Twyman, 1996; Mathews et al., 1996). This pharmacological property of benzodiazepines has been the basis for two recent reports challenging the hypothesis that the peak GABA levels are invariably saturating at all inhibitory synapses (Frerking et al., 1995; Perrais and Ropert, 1997). In both cases, investigators found that benzodiazepines augmented the peak amplitudes of mIPSCs.

Diethyl-lactam and the other lactones have a more complicated effect on the GABA concentration-response relationship than benzodiazepines, decreasing both the $\mathrm{EC}_{50}$ for $\mathrm{GABA}$ and the slope. Evidence supporting different sites and mechanisms for these two classes of GABA modulatory agents is the lack of effect of the benzodiazepine antagonist flumazenil on the enhancement of GABA-induced currents by other lactones and the failure of lactones to influence benzodiazepine binding (Holland et al., 1990; Williams et al., 1997).

Based on a previously published model of $\mathrm{GABA}_{\mathrm{A}}$ receptor kinetics, there are several potential explanations for diethyllactam's effects on IPSCs, mIPSCs, patch currents, and the GABA dose-response curve. First, there could be a selective effect on transitions into the monoliganded $\mathrm{GABA}_{\mathrm{A}}$ receptor open state $\left(\mathrm{GR}^{\circ}\right)$ (Fig. $\left.7 A\right)$. We can qualitatively simulate our experimental data if the binding of diethyl-lactam to the $\mathrm{GABA}_{\mathrm{A}}$ receptor increases the opening rate constant $\left(O_{1}\right)$ for the monoliganded receptor from 200 to $610 \mathrm{sec}^{-1}$ (Fig. $7 B-D$ ). The current 
values obtained from the simulation show little potentiation by diethyl-lactam at GABA concentrations $>60 \mu \mathrm{M}$, in agreement with our actual results (compare Figs. $2 C, 7 B$ ). The concentration responses do not completely overlap, reflecting the simplifications in our model and the fact that the standard logistic equation will not provide the best fit for a two-product reaction.

Second, alterations in the GABA-binding constants $k_{\mathrm{F}}$ and $k_{\mathrm{B}}$ could produce a similar prolongation of the model IPSC in the presence of diethyl-lactam. However, we have previous binding and electrophysiological data that suggest no direct interaction between $\gamma$-butyrolactones and the GABA recognition site of the receptor, so an effect of diethyl-lactam on $k_{\mathrm{F}}$ and $k_{\mathrm{B}}$, although possible, seems unlikely (Holland et al., 1990; Mathews et al., 1996). Third, if the desensitization rate constants $d_{1}$ or $r_{1}$ are altered by diethyl-lactam, the model will also generate current responses consistent with our experimental results. Indeed, Z hu and Vicini (1997) propose that neurosteroid enhancement of inhibition occurs through such a mechanism. Detailed singlechannel studies will be required to determine the exact kinetic step(s) altered by diethyl-lactam.

We also need to emphasize that the specific model of the $\mathrm{GABA}_{\mathrm{A}}$ receptor we selected for our simulations is not uniquely required for our conclusions. We could have used several other models of the $\mathrm{GABA}_{\mathrm{A}}$ receptor that also contain monoliganded open states and obtained similar results (Bormann and Clapham, 1985; Weiss and Magleby, 1989; Macdonald et al., 1989a). The critical variable in this simulation will be the time course of the synaptic GABA concentration, which must have a longer contribution by subsaturating GABA concentrations than the rapid concentration jump used in our patch experiments. Furthermore, any model of synaptic transmission like the one we propose is an oversimplification because the actual concentration of neurotransmitter at postsynaptic receptors will be a complicated function of the cleft surface area, the cleft configuration, and time (Clements et al., 1992; Clements, 1996).

Independent of any specific model or rate constant alteration, we have shown that there must be a significant period during the IPSC when $\mathrm{GABA}_{\mathrm{A}}$ receptors are not saturated. This relative "mismatch" between neurotransmitter concentration and postsynaptic receptor density in some regions may play an important physiological role, allowing modulation of the temporal spread of IPSCs by substances such as benzodiazepines and $\gamma$-butyrolactones. Although this and related studies have focused on pharmacological modulation, we anticipate the discovery of endogenous neuromodulatory agents that act by a similar mechanism (Olasmaa et al., 1990; Rothstein et al., 1992a,b).

\section{REFERENCES}

Banks MI, Li T, Pearce RA (1997) Effects of isoflurane on mIPSCs and

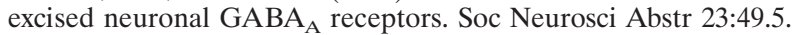

Bormann J, Clapham DE (1985) gamma-Aminobutyric acid receptor channels in adrenal chromaffin cells: a patch-clamp study. Proc Natl Acad Sci USA 82:2168-2172.

Braestrup C, Nielsen EB, Sonnewald U, Knutsen LJS, Andersen KE, Jansen JA, Frederiksen K, Andersen PH, Mortensen A, Suzdak PD (1990) (R)- $N$-[4,4-bis(3-methyl-2-thienyl)but-3-en-1-yl]nipecotic acid binds with high affinity to the brain $\gamma$-aminobutyric acid uptake carrier. J Neurochem 54:639-647.

Canney DJ, Holland KD, Levine JA, McKeon AC, Ferrendelli JA, Covey DF (1991) Synthesis and structure-activity studies of alkyl-substituted gamma-butyrolactones and gamma-thiobutyrolactones: ligands for the picrotoxin receptor. J Med Chem 34:1460-1467.

Choi DW, Farb DH, Fischbach GD (1981) Chlordiazepoxide selectively potentiates GABA conductance of spinal cord and sensory neurons in cell culture. J Neurophysiol 45:621-631.

Clements JD (1996) Transmitter timecourse in the synaptic cleft: its role in central synaptic function. Trends Neurosci 19:163-171.

Clements JD, Lester RA, Tong G, Jahr CE, Westbrook GL (1992) The time course of glutamate in the synaptic cleft. Science 258:1498-1501.

Destexhe A, Sejnowski TJ (1995) G-protein activation kinetics and spillover of gamma-aminobutyric acid may account for differences between inhibitory responses in the hippocampus and thalamus. Proc Natl Acad Sci USA 92:9515-9519.

Draguhn A, Heinemann U (1996) Different mechanisms regulate IPSC kinetics in early postnatal and juvenile hippocampal granule cells. J Neurophysiol 76:3983-3993.

Frerking M, Borges S, Wilson M (1995) Variation in GABA mini amplitude is the consequence of variation in transmitter concentration. Neuron 15:885-895.

Frosch MP, Lipton SA, Dichter MA (1992) Desensitization of GABAactivated currents and channels in cultured cortical neurons. J Neurosci 12:3042-3053.

Galarreta M, Hestrin S (1997) Properties of GABA $_{A}$ receptors underlying inhibitory synaptic currents in neocortical pyramidal neurons. J Neurosci 17:7220-7227.

Holland KD, McKeon AC, Covey DF, Ferrendelli JA (1990) Binding interactions of convulsant and anticonvulsant $\gamma$-butyrolactones and $\gamma$-thiobutyrolactones with the picrotoxin receptor. J Pharmacol Exp Ther 254:578-583.

Holland KD, Mathews GC, Bolos-Sy AM, Tucker JB, Reddy PA, Covey DF, Ferrendelli JA, Rothman SM (1995) Dual modulation of the gamma-aminobutyric acid type A receptor/ionophore by alkylsubstituted gamma-butyrolactones. Mol Pharmacol 47:1217-1223.

Isaacson JS, Solis JM, Nicoll RA (1993) Local and diffuse synaptic actions of GABA in the hippocampus. Neuron 10:165-175.

Jones MV, Westbrook GL (1995) Desensitized states prolong GABA channel responses to brief agonist pulses. Neuron 15:181-191.

Klunk WE, Covey DF, Ferrendelli JA (1982a) Anticonvulsant properties of alpha, gamma, and alpha, gamma-substituted gammabutyrolactones. Mol Pharmacol 22:438-443.

Klunk WE, McKeon A, Covey DF, Ferrendelli JA (1982b) Alphasubstituted gamma-butyrolactones: new class of anticonvulsant drugs. Science 217:1040-1042.

Lavoie AM, Twyman RE (1996) Direct evidence for diazepam modulation of $\mathrm{GABA}_{\mathrm{A}}$ receptor microscopic affinity. Neuropharmacology 35:1383-1392.

Macdonald RL, Rogers CJ, Twyman RE (1989a) Kinetic properties of the $\mathrm{GABA}_{\mathrm{A}}$ receptor main conductance state of mouse spinal cord neurones in culture. J Physiol (Lond) 410:479-499.

Macdonald RL, Rogers CJ, Twyman RE (1989b) Barbiturate regulation of kinetic properties of the $\mathrm{GABA}_{\mathrm{A}}$ receptor channel of mouse spinal neurones in culture. J Physiol (Lond) 417:483-500.

Maconochie DJ, Zempel JM, Steinbach JH (1994) How quickly can $\mathrm{GABA}_{\mathrm{A}}$ receptors open? Neuron 12:61-71.

Mathews GC, Bolos-Sy AM, Covey DF, Rothman SM, Ferrendelli JA (1996) Physiological comparison of alpha-ethyl-alpha-methyl-gammathiobutyrolactone with benzodiazepine and barbiturate modulators of $\mathrm{GABA}_{\mathrm{A}}$ receptors. Neuropharmacology 35:123-136.

Mennerick S, Que J, Benz A, Zorumski CF (1995) Passive and synaptic properties of hippocampal neurons grown in microcultures and in mass cultures. J Neurophysiol 73:320-332.

Mody I, De Koninck Y, Otis TS, Soltesz I (1994) Bridging the cleft at GABA synapses in the brain. Trends Neurosci 17:517-525.

Olasmaa M, Rothstein JD, Guidotti A, Weber RJ, Paul SM, Spector S, Zeneroli ML, Baraldi M, Costa E (1990) Endogenous benzodiazepine receptor ligands in human and animal hepatic encephalopathy. J Neurochem 55:2015-2023.

Perrais D, Ropert N (1997) Effects of zolpidem on mIPSCs and occupancy of $\mathrm{GABA}_{\mathrm{A}}$ receptors in central synapses. Soc Neurosci Abstr 23:950.

Reddy PA, Hsiang BC, Latifi TN, Hill MW, Woodward KE, Rothman SM, Ferrendelli JA, Covey DF (1996) 3,3-Dialkyl- and 3-alkyl-3benzyl-substituted 2-pyrrolidinones: a new class of anticonvulsant agents. J Med Chem 39:1898-1906.

Reddy PA, Woodward KE, McIlheran SM, Hsiang BC, Latifi TN, Hill MW, Rothman SM, Ferrendelli JA, Covey DF (1997) Synthesis and 
anticonvulsant activities of 3,3-dialkyl- and 3-alkyl-3-benzyl-2piperidinones ( $\delta$-valerolactams) and hexahydro-2H-azepin-2-ones ( $\epsilon$-caprolactams). J Med Chem 40:44-49.

Roepstorff A, Lambert JD (1992) Comparison of the effect of the GABA uptake blockers, tiagabine and nipecotic acid, on inhibitory synaptic efficacy in hippocampal CA1 neurones. Neurosci Lett 146:131-134.

Roepstorff A, Lambert JD (1994) Factors contributing to the decay of the stimulus-evoked IPSC in rat hippocampal CA1 neurons. J Neurophysiol 72:2911-2926.

Rogers CJ, Twyman RE, Macdonald RL (1994) Benzodiazepine and $\beta$-carboline regulation of single $\mathrm{GABA}_{\mathrm{A}}$ receptor channels of mouse spinal neurones in culture. J Physiol (Lond) 475:69-82.

Rothstein JD, Garland W, Puia G, Guidotti A, Weber RJ, Costa E (1992a) Purification and characterization of naturally occurring benzodiazepine receptor ligands in rat and human brain. J Neurochem 58:2102-2115.

Rothstein JD, Guidotti A, Costa E (1992b) Release of endogenous ben- zodiazepine receptor ligands (endozepines) from cultured neurons. Neurosci Lett 143:210-214.

Tia S, Wang JF, Kotchabhakdi N, Vicini S (1996) Distinct deactivation and desensitization kinetics of recombinant $\mathrm{GABA}_{\mathrm{A}}$ receptors. Neuropharmacology 35:1375-1382.

Twyman RE, Macdonald RL (1992) Neurosteroid regulation of $\mathrm{GABA}_{\mathrm{A}}$ receptor single-channel kinetic properties of mouse spinal cord neurons in culture. J Physiol (Lond) 456:215-245.

Weiss DS, Magleby KL (1989) Gating scheme for single GABAactivated Cl- channels determined from stability plots, dwell-time distributions, and adjacent-interval durations. J Neurosci 9:1314-1324.

Williams KL, Tucker JB, White GW, Weiss DS, Ferrendelli JA, Covey DF, Krause JE, Rothman SM (1997) Lactone modulation of the $\mathrm{GABA}_{\mathrm{A}}$ receptor: evidence for a positive modulatory site. Mol Pharmacol 52:114-119.

Zhu WJ, Vicini S (1997) Neurosteroid prolongs GABA $_{\mathrm{A}}$ channel deactivation by altering kinetics of desensitized states. J Neurosci 17: 4022-4031. 